\title{
A Study of the Effects of Mindfulness in Five Primary Schools
} in New Zealand

\author{
New Zealand Journal of Teachers' Work, Volume 11, Issue 2, 201-220, 2014
}

\author{
GRANT RIX \\ Mental Health Foundation of New Zealand (Tauranga) \\ ROSS BERNAY \\ Auckland University of Technology
}

\begin{abstract}
This study investigated the effects of an eight-week mindfulness in schools programme delivered in five primary schools in New Zealand. The participants included 126 students ranging in age from 6-11 years old and six classroom teachers. The programme was developed by one of our researchers (Rix) to align with The New Zealand Curriculum (Ministry of Education, 2007) and with a bi-cultural focus in mind. A Māori model of hauora (holistic well-being), Te Whare Tapa Wha, was incorporated as a key element of the programme. Te Whare Tapa Wha describes a Māori perspective on health and well-being which suggests that the house (whare) and its parts are viewed as a metaphor for different aspects of one's health such that if one part of a house (or one's health) is not in order, then there will be an effect of the other parts of the house (an individual's health). Thus, physical health, spiritual health, family health and mental health are all interconnected for a person's well-being, which is also a critical aspect of mindfulness. Classroom teachers were asked to complete fortnightly journal entries as part of a qualitative analysis of the effectiveness of the programme. A follow-up survey was completed three months after the last mindfulness class to assess any potential long term effects. Findings suggest that the programme may be efficacious for increasing calm, reduced stress, and improved focus and attention. In addition, results indicated enhanced selfawareness, and the development of positive relationships. A number of these outcomes were observed in both students and classroom teachers. These findings suggest that mindfulness practice can make a strong contribution to the key competencies outlined in the New Zealand curriculum. The design of the programme, findings of the study, and future recommendations for implementing mindfulness practice in New Zealand schools are discussed.
\end{abstract}

\section{INTRODUCTION}

While most studies of mindfulness in the health arena focus on 'fixing' the patient or treating their symptoms, our research highlights the positive wellbeing benefits for everyone. Although there is limited research on mindfulness within the New Zealand context, our study aimed to add to that research by 
introducing mindfulness to groups of children in various schools across New Zealand.

Children may face a myriad of societal, economic and family-related issues that might affect their individual well-being. Such stressful life events have been shown to be related to lowered academic performance (Kiselica, Baker, Thomas, \& Reedy, 1994; cited in Napoli, Krech, \& Holley, 2005). Research examining the effects of stress reduction programmes in schools from the 1980s and 1990s, has already indicated improvements in academic performance, self-esteem, mood, concentration, and behaviour (Dendato \& Deiner, 1986; Kiselica, Baker, Thomas, \& Reedy, 1994). Rather than propose mindfulness as a 'fix-it' for these stressful events, this research points to the possibilities of mindfulness supporting positive well-being development for all children.

To date, the majority of research into the benefits of mindfulness practise has been conducted with adult populations. However, there is a growing body of research exploring the ways mindfulness can support the general well-being and academic performance of children and adolescents. The majority of this research has so far occurred in the United States and to a lesser degree in the United Kingdom. At least one study has been conducted among primary school children in Australia (Joyce, Etty-Zeal, Zazryn, Hamilton, \& Hassed, 2010).

The aim of our study was to add to this growing body of research into the effects of mindfulness in promoting well-being in children. By providing an eight week mindfulness programme adapted for children in five primary schools across New Zealand entitled the 'Mindful Classroom' curriculum, would children demonstrate enhanced social emotional competence and interpersonal relationships by building mindfulness skills, and therefore improve well-being? Rather than propose mindfulness as a 'fix-it' for stressful events, our research points to the positive well-being benefits for all children.

\section{LITERATURE REVIEW}

\section{What is mindfulness?}

Mindfulness is the practice of giving our full, open-hearted attentiveness to what is immediately occurring, physically and mentally, both within and around us. There are many other ways to describe mindfulness highlighting aspects such as focused awareness, the present moment, and non-judgment (Bishop, et al., 2004; Kabat-Zinn, 2005; Siegel, 2007). The online Oxford English Dictionary (http://www.oed.com) defines mindfulness or being mindful as: "taking heed; being conscious or aware". Some researchers add the component of compassion to this definition (Gilbert, 2009). Despite the fact that there are a variety of definitions of mindfulness, the generally accepted core practices are:

1. intentionally focusing and sustaining attention on immediate experience; and

adopting a curious, open and accepting orientation towards that experience (Bishop, et al., 2004; Kabat-Zinn, 2005; Shapiro, Carlson, Astin, \& Freedman, 2006).

Mindfulness can be described by a series of subskills measured by various assessment instruments including self-awareness and regulation (Brown \& Ryan, 2003), openness to new information (Bodner \& Langer, 2001), 
attention (Fan, McCandliss, Sommer, Raz, \& Posner, 2002), and nonjudgement of experiences (Baer, Smith, Hopkins, Krietemeyer, \& Toney, 2006). A range of benefits have been noted for individuals using mindfulness across various studies; many of which are confirmed by more than one study. A sample of these are included here: reduced stress and anxiety (Ludwig \& Kabat-Zinn, 2008; Siegel, 2010; Willis, 2007); improved sleep patterns (Britton, Haynes, Fridel, \& Bootzin, 2010; Ludwig \& Kabat-Zinn, 2008; Yook, et al., 2008); improved attention (Jha, Krompinger \& Baime, 2007; Semple \& Lee, 2008; Tang, et al., 2007); improved mental outlook (Brown \& Langer, 1990; Wenk-Sormaz 2005); learning, memory, attention, sensory processing, empathy and reduced fear (Mental Health Foundation, 2011). Although there are other research investigations that corroborate these findings across different countries, most of these studies have small sample sizes. Further, these studies often rely solely on self-reporting and do not have a randomised control group comparison. Research is needed with larger sample sizes and quantitative instruments. These investigations could measure mindfulness itself as well as the components of mindfulness. One component of mindfulness that has been assessed is attention through an online computer test (Jha, et al., 2007). Other mindfulness studies focus on physiological testing (stress cortisol levels) or note improvements in cognitive abilities by reviewing academic marks or completed self and peer reports (Schonert-Reichl, et al., 2015). Social emotional skills and reductions in depression and anxiety have also been measured (SchonertReichl, et al., 2015).

There are limited studies in Aotearoa New Zealand. Fogarty (2009) conducted a study of mindfulness practitioners and their responses to stress measured by stress cortisol levels. Although a small sample size, the quantitative measure showed that mindfulness practitioners returned to a more stabilised emotional state faster than non-practitioners. A second study completed in Aotearoa New Zealand was conducted at Waikato University and focused on a wait-list controlled, random assignment study of patients with chronic illness (Simpson \& Mapel, 2011). Using the Kentucky Inventory of Mindfulness Skills (KIMS) survey (Baer, et al., 2004), improvements in everyday mindfulness were noted alongside reductions in depression and anxiety. This small study is a significant local research that demonstrated short term benefit retention after a six-month follow-up. Although there are a number of mindfulness trainers across New Zealand, there is very limited research into the effectiveness of mindfulness in New Zealand. Of particular concern is the variability of quality of these programmes; most of which do not have evidencebased research to document positive effects for clients/patients.

\section{Mindfulness Programmes for Learners in the Pre-School and School Settings}

There are a growing number of research studies investigating the effects of mindfulness for children, but no articles were found for mindfulness programmes for children in New Zealand. In this section, a review of these studies shows a variety of positive benefits noted from a series of intervention studies based on self-reports, parent and teacher observations.

Hart (2001a) found that students felt an emotional connection, and identified the relevance more readily of classroom programmes which made them more alert when mindfulness activities were included. Mindfulness 
provides children the opportunity to build awareness which enhances their academic study. According to Hart (2001b), the awareness process is not difficult; I (Bernay) would disagree as most of my students find focusing activities very difficult without large amounts of regular practice.

Brady (2004), however, concurred with Hart's emphasis on contemplative practice in education. He suggested that by practicing contemplative exercises, the frequency of healthy thoughts increases and negative thoughts were viewed with less anxiety. Students became aware of thoughts, feelings and actions while engaged in learning, but did not get caught up in them. Once they reached this level of awareness, students actually noticed, for themselves, the increased learning that occurred when using mindfulness.

Seven specific programmes were reviewed that reflect a similar kind of mindfulness programme for children to the one presented to children in this study: MindUp (Hawn Foundation, 2011); Inner Kids (Kaiser Greenland, 2010); WellnessWorks (Kinder, 2008); Still Quiet Place (Saltzman \& Goldin, 2008); Inner Resilience (Lantieri, 2008); Attention Academy (Napoli, Roch Krech \& Holley, 2005) and the Mindfulness Schools Programme (Biegel \& Brown, nd). Generally, children are introduced to a modified series of focusing, calming activities over an 8 week period similar to the ones introduced to adults. The positive results from these studies highlighted the need to conduct a similar study in New Zealand with a mindfulness curriculum that reflected the context of Aotearoa New Zealand. In addition, this study used teacher reports to gauge improvements which was one tool used in the studies conducted by Desmond \& Hanich, 2010; Flook, et al. (2008); Flook, et al. (2010); Kinder (2008); and Napoli, Krech, \& Holley (2010), detailed below.

The Hawn Foundation (2011) of British Columbia, Canada, developed the MindUp curriculum used by teachers in the Vancouver School Board as part of the Social Emotional Learning programme (Schonert-Reichl \& Stewart Lawlor, 2010). The goals of the programme include: improved self-awareness, memory, regulation of emotions and executive functions of the pre-frontal cortex of the brain (Willis, 2007). Schonert-Reichl and Stewart-Lawlor (2007a; 2007b) have conducted studies of the MindUp programme across four schools with a total of two hundred forty-six students and noted gains in several of the goal areas.

The InnerKids programme included focusing exercises, sitting meditation, and compassion exercises such as sending out good messages to specific people (Kaiser Greenland, 2010). Parents and teachers of sixty-four students in one of the studies of InnerKids curriculum reported improvements in attention and behaviour (Flook, et al., 2010). Other benefits noted included improved executive function (memory, planning, metacognition, self-regulation), even after only limited exposure to the techniques encouraging the use of mindfulness in classrooms (Flook et al., 2008; Flook, et al., 2010).

In Lancaster, Pennsylvania, WellnessWorks, an in-school programme which combined mind/body activities including yoga, breath work, attention building skills and compassion exercises (Kinder, 2008; Desmond \& Hanich, 2010) demonstrated similar results. The forty-six students in this study assessed their own progress, and indicated improvements which were also noted by their teachers and the school principal. An overall improvement for the students in this study was noted in mental, emotional, physical and social 
competencies on a behaviour rubric completed by teachers; these results were duplicated in three other randomised control studies (Desmond \& Hanich, 2010).

Amy Saltzman's Still Quiet Place Programme, based in Palo Alto, California, adapted a number of mindfulness exercises for children with a focus on recognising the 'still quiet' aspect of the mind that becomes increasingly recognised through meditation practice (Saltzman \& Goldin, 2008). In a study of twenty-four families, improved attention and focus scores on the Attention Network Test (ANT) were demonstrated (Fan, et al., 2002) rather than through self-reporting (Saltzman \& Goldin, 2008). Quieting the mental chatter is key to the Inner Resilience Programme, designed by Lantieri (2008) in New York City, who discussed the importance of active participation in her mindfulness intervention programmes which helped participants to slow down to focus on what was happening in each moment.

In the Attention Academy in Arizona, which included body scan, breath focus, mindful movement and sensori-motor activities, more significant gains in attention and focus were achieved compared to a control group, replicated several times with two hundred fifty-four students. Teachers also noted fewer behaviour issues impacting on learning time (Napoli, et al., 2005). The Mindful Schools (2012a; 2012b) Programme of Oakland, California has reached over 18000 children and Biegel and Brown (nd) found that attention and social skills had greatly improved and were sustained after a three-month post-intervention review. In addition, Joyce, et al. (2010) noted that $14 \%$ of Australian children have a significant mental health problem. In their study in Melbourne, base line figures showed $25.6 \%$ of the student sample fell in the borderline or diagnostic category of the Strengths and Difficulties Questionnaire (SDQ) which reduced to $16.3 \%$ following the completion of a 10-week mindfulness in schools programme.

To review, the research studies of these seven mindfulness programmes for children reported positive benefits which included improvements in: stress reduction and coping, executive function, social-emotional competencies, attention, and general well-being. In summary, these positive results following the introduction of mindfulness into school mental health programmes suggest further exploration and research is indicated, and therefore a series of studies in New Zealand would contribute to the research in this growing field. Although many positive benefits are highlighted, it is important to note that many of these studies were designed to promote the use of a specific mindfulness programme. The positive results indicate the need for further longitudinal studies, in a variety of settings, using quantitative instruments and a randomised control design.

\section{Mindfulness in the New Zealand Curriculum}

The benefits of mindfulness practice, highlighted in the literature review above, resonate well with various aspects of the New Zealand Curriculum (NZC) (2007). Mindfulness can be linked to the key competencies and the Health and Physical Education, Science and Social Sciences learning areas of the NZC (2007). In addition, links can be shown to Te Whare Tapa Wha, a model of hauora (holistic well-being) from a Māori perspective used in New Zealand schools. 
Mindfulness practice potentially develops four of the five key competencies (thinking, managing self, relating to others, and participating and contributing) that the NZC recognises as paramount for good functioning at school and in society. In relation to thinking: mindfulness practice aims to develop kindness and curiosity about what is occurring in each moment, and independent thinking which lays the foundation for a life of inquiry. Children may also experience a greater ability to manage self as evidenced in the fact that mindfulness practice cultivates self-acceptance and self-regulation. This allows students to manage themselves better by choosing their behaviours based on mindful attentiveness rather than impulsive reactivity. For relating to others, mindfulness promotes a non-judgmental attitude toward self and others and fosters positive connections between self, others and nature. And, for participating and contributing, mindfulness has been shown to effect positive changes to the brain in areas responsible for empathy and compassion (Hölzel, et. al., 2011), which are qualities that can increase one's sense of belonging and contribute to positive and meaningful action.

Learning mindfulness practices can touch on many areas of the curriculum, but is most attuned with the "Health \& Physical Education", "Science" and "Social Sciences" learning areas. In terms of "Health and Physical Education", mindfulness can contribute to personal growth and development, through physical activities which may contribute to well-being and help students to develop a stronger sense of personal identity through the exploration of feelings, beliefs and actions. Mindfulness has been shown to support the development of identity, sensitivity and respect, and a deeper understanding of students' relationships with others. When learning about mindfulness in Science, students can explore how the brain works and the effects mindfulness has on the brain and changes in hormones and neurotransmitters (Siegel, 2007).

In terms of "Social Sciences", mindfulness may enhance students' understanding of the choices they make, how they understand their own and other people's wants and needs, and understandings of health and well-being which derive from other cultures, including in particular Māori understandings of hauora through Te Whare Tapa Wha. When presented in combination with Te Whare Tapa Wha, mindfulness practices may assist with the development of a holistic understanding of well-being by providing the opportunity to develop personal resources in the four domains of experience represented by Te Whare Tapa Wha (see figure 1 on the next page). Specifically, the current programme used breath and body based practices for exploring the interplay between physical sensations, thoughts, emotions, relationships with others, and interconnectedness with the natural world (thus also establishing the link with taha whenua (family health)-represented by the floor of Te Whare Tapa Wha). 


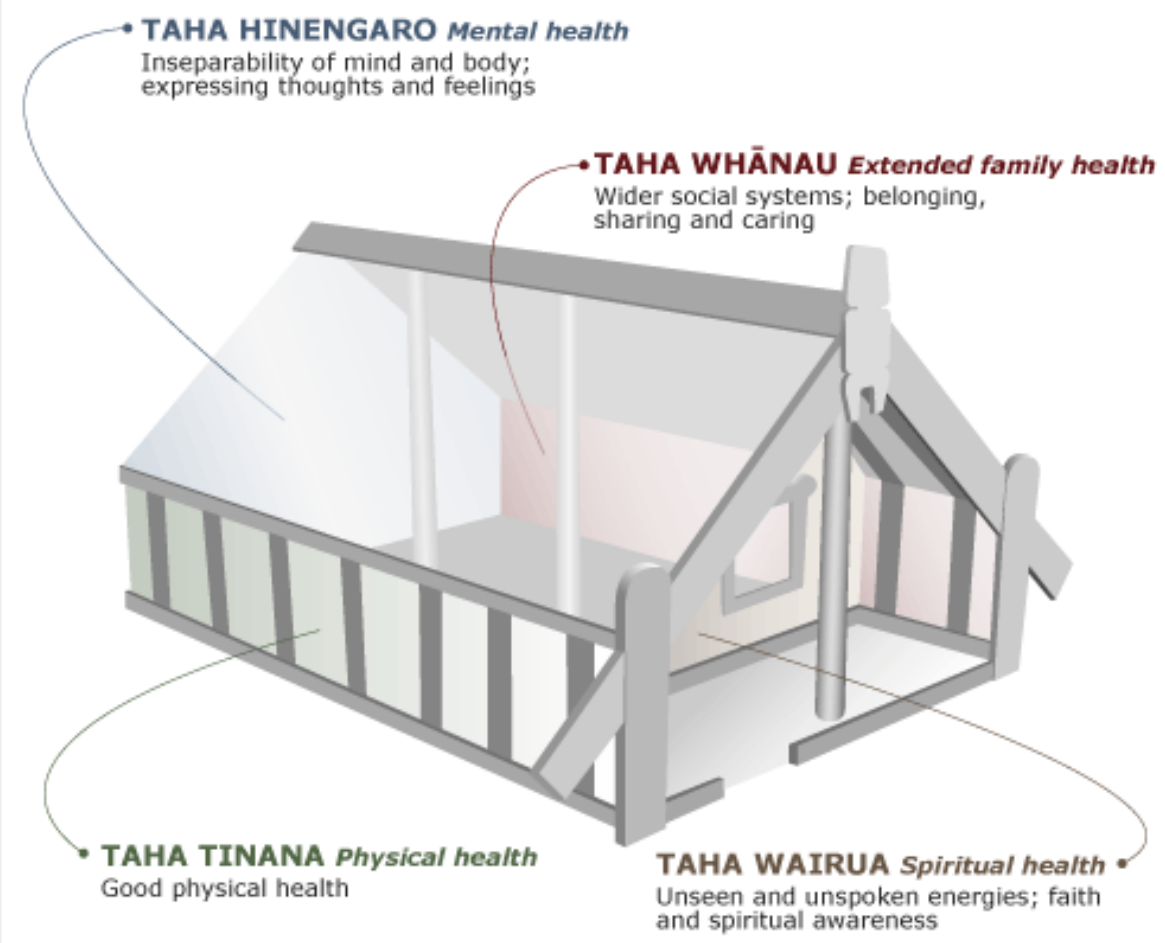

Fig. 1 Te Whare Tapa Wha

Individuals learning mindfulness are introduced to a variety of exercises by a mindfulness practitioner generally in a group setting over an 8 week period. These exercises can also be practiced at home. In this study, a specially designed eight week mindfulness programme was delivered by a mindfulness facilitator one hour per week in the children's classroom. The exercises were reviewed during the week by the classroom teacher when possible. The purpose of these exercises is to promote the development of mindfulness in day to day activities. In other words, by focusing awareness in the moment nonjudgementally, an individual might be able to process more information, and use that information to more consciously make decisions and choices. Practicing mindfulness may help individuals learn to rebalance and sustain well-being rather than being caught up in ruminating thoughts or distractions or reacting impulsively.

\section{THE RESEARCH STUDY}

\section{Approach to the research}

The design for our research pilot project was a qualitative approach within the interpretive paradigm to review five individual case studies where a mindfulness intervention was used to ascertain well-being benefits. We chose qualitative interpretive research which allowed us to focus on the participants' experiences and what was significant for them (Denzin \& Lincoln, 1994). Qualitative research allowed us to listen to the participants' thoughts and 
conclusions to assess results. The perceptions of the effects of mindfulness are derived directly from the participants' reality (Gall, J.P., Gall, M.D \& Borg, 2005); the ideas, thoughts and feelings came from the participants which we then interpreted and analysed in order to make some conclusions about the mindfulness intervention. A case study approach was used as an opportunity to look at individuals and their contexts to describe their experiences (Stake, 1995).

\section{The research context}

In our research, we looked at five primary schools (see Table 1) across New Zealand; each school represented a case study of the effects of an eight week mindfulness intervention. The intervention is described in the next section (research design). A total of 126 students participated in this study in the schools described below; the same mindfulness facilitator presented to students in schools 1-4; and the mindfulness facilitator for school 5 had a similar background and preparation to the facilitator for the Auckland schools.

\section{Research design}

During term two (May-June) 2013, the Mental Health Foundation of New Zealand (MHF) delivered an eight week mindfulness intervention programme to primary aged children (6-11 years old) across these five New Zealand schools. The programme was developed by one of the authors (Rix) who has extensive mindfulness training and teaching experience to align with the New Zealand Curriculum and with a bi-cultural focus in mind. Te Whare Tapa Wha was incorporated as a key element of the programme. The programme covered themes of breath-body awareness, sensory awareness, practices for promoting kindness and gratitude, emotion-regulation, and interconnectedness. Students were taught breath awareness activities as well as mindful eating (paying attention to each bite; noticing the sensory experience of eating); mindful movement (a modified yoga programme); body scan (paying specific attention to each part of the body); mindful walking (noticing in the body each part of each step that one takes); a happy heart practice to learn about lovingkindness; and practices for recognising the interdependence between oneself and the natural world.

Classroom teachers were asked to complete fortnightly journal entries as part of a qualitative measure which would later be interpreted to note changes in behaviour as indicators of well-being. To review sustained effects, a final journal entry was completed three months after the last mindfulness class to assess any potential long term effects. In a qualitative case study design such as this, a holistic picture of the participants is derived from answers to open ended questions (Creswell, 1994; Crotty, 1998) in the journals. Journals were also used in these cases studies as Van Manen (1990) suggests that journals provide an opportunity for participants to reveal new information from their thoughts and feelings which was our purpose for using interpretive design. 


\begin{tabular}{|c|c|c|c|}
\hline & $\begin{array}{l}\text { School } \\
\text { description }\end{array}$ & Student population & Class description \\
\hline School 1 & $\begin{array}{l}\text { Less than } 300 \\
\text { students } \\
\text { Located in central } \\
\text { Auckland }\end{array}$ & $\begin{array}{l}\text { Mostly Māori and Pasifika } \\
\text { children }\end{array}$ & $\begin{array}{l}\text { Composite year } 4 / 5 \text { class with } 28 \\
\text { students }\end{array}$ \\
\hline School 2 & $\begin{array}{l}\text { Less than } 125 \\
\text { students } \\
\text { Low } \\
\text { socioeconomic } \\
\text { urban area } \\
\text { outside of central } \\
\text { Auckland }\end{array}$ & $\begin{array}{l}\text { Large Māori student } \\
\text { population }(24 \%) ; \\
16 \% \text { NZ European; } \\
\text { Samoan, Tongan and Filipino } \\
\text { students each represented } \\
\text { nearly } 25 \% \\
\text { Over } 50 \% \text { of the students } \\
\text { speak English as an } \\
\text { additional language. }\end{array}$ & $\begin{array}{l}25 \text { Year } 3 / 4 \text { students learned the } \\
\text { mindfulness practices. There were } \\
\text { some concerns about the long term } \\
\text { effects in this school as the teacher left } \\
\text { at the end of the term, but subsequent } \\
\text { analysis has shown that the } \\
\text { mindfulness gains continued for these } \\
\text { students. }\end{array}$ \\
\hline School 3 & $\begin{array}{l}\text { Over } 500 \\
\text { students } \\
\text { Decile } 10 \\
\text { Inner city } \\
\text { Auckland }\end{array}$ & $\begin{array}{l}\text { Predominately } \\
\text { NZ European } \\
\text { All other ethnic groups } \\
\text { represent } 10 \% \text { or fewer } \\
\text { students. }\end{array}$ & $\begin{array}{l}\text { The participants from this school were } \\
\text { the youngest; } 22 \text { year } 2 \text { children. This } \\
\text { did not hamper them in any way as } \\
\text { they completed all the activities without } \\
\text { a problem. The stable, well-organised } \\
\text { environment in this school had a } \\
\text { positive impact on the uptake for the } \\
\text { children even though they were so } \\
\text { young. }\end{array}$ \\
\hline School 4 & $\begin{array}{l}\text { Located in central } \\
\text { Auckland } \\
\text { Less than } 300 \\
\text { students }\end{array}$ & $\begin{array}{l}\text { A very multicultural mix with } \\
\text { the highest proportion of } \\
\text { students being New Zealand } \\
\text { European }(20 \%) \text { with } \\
\text { students from across the } \\
\text { world. }\end{array}$ & $\begin{array}{l}\text { A composite class of } 27 \text { Year } 5 / 6 \\
\text { students from School } 4 \text {. Although the } \\
\text { class in this school appeared to } \\
\text { engage the least with the practices } \\
\text { when the mindfulness teacher was not } \\
\text { in the school, their progress equal to } \\
\text { all the other schools was noted by the } \\
\text { mindfulness facilitator and the } \\
\text { classroom teacher. }\end{array}$ \\
\hline School 5 & $\begin{array}{l}\text { South Island } \\
\text { Small school } \\
\text { Rural area }\end{array}$ & Mostly NZ European & 24 Year $4 / 5$ students \\
\hline
\end{tabular}

Table 1 School description

The classroom teachers observed the children in their class to write detailed descriptions of the children's behaviour before, during and after the children have been introduced to mindfulness. Prompts for the journal entries completed by the teachers were provided to initiate their thoughts prior to writing. Open-ended questions were used in the journals to elicit a range of information. In the journals, the classroom teachers were asked the following questions: 'please tell me about your children's engagement with activities presented; your own personal engagement with activities presented; children's social interactions; classroom behaviour including attention/focus; participation and engagement in class; and anything else you wish to comment on' (Gall, J.P., Gall, M.D., \& Borg, 2005). Teachers complete behavioural observations of students on a regular basis and therefore completing these journals was consistent with ongoing assessment procedures and could therefore provide useful data for interpretive analysis. 


\section{DATA COLLECTION AND ANALYSIS}

Each teacher in each of the five schools completed a journal based on a series of prompts each fortnight during the intervention and one term after the intervention was completed. A thematic analysis was completed of these journals to initiate a report of the results. Initial patterns were noted first from what was directly stated in the journal responses from the teacher's experiences (Braun \& Clark (2006). After we reviewed these initial details, Bernay reviewed the journals a second time for broader themes (Braun \& Clark, 2006). Rix then reviewed the journals and cross-checked the themes that had emerged. A discussion followed and the final themes were chosen. The specific themes initially clustered around several key ideas that were reflected in previous research:

1. Amount of student engagement with activities (practices) and students' sense of calm and less agitation (Flook, et al., 2010);

2. Students' ability to focus and pay attention (being in the present moment) (Kabat-Zinn, 2005);

3. Students' compassion towards self and others (Gilbert, 2009) as highlighted in improved relational skills and conflict resolution; and

4. Increased calm and stress reduction for teachers through their own engagement with the practices.

The first three key findings were focused upon initially as they link to the definitions of mindfulness discussed earlier and potential benefits described in previous research studies. The final theme, the role of teacher engagement, was reviewed to contribute to the discussion of the importance of the teacher of mindfulness (preferably the classroom teacher him/herself rather than an outside facilitator) being a mindfulness practitioner. Kabat-Zinn (2005) argues that the teacher and researcher should be mindfulness practitioners.

\section{Key finding 1: Amount of student engagement and students' sense of calm}

In school 1, each week the students were actively engaged in the activities but responded particularly well to the activities related to connectedness to the world. The teacher noted that students applied the information learned in the activities to everyday situations including difficult situations or conflicts. Children in school 2 were actively engaged in the activities presented from the third session, and were particularly engaged in the happy heart practice (a practice for fostering kindness towards others). The teacher in school 3 discovered that due to their involvement in the activities children were very calm after the mindfulness instructor left. By week 6 , she reported an 'enduring sense of calm'. The journal from school 4 reported "students really enjoy the practices and report on feeling relaxed, peaceful, refreshed mentally, etc.". In school 4, reports of students feeling relaxed, peaceful and refreshed were made following session 2 . This theme is repeated in the follow-up survey for school 4. And in school 5, the teacher noted the positive mood in the classroom during the mindfulness activities: "the students were centred and calm and know what to expect".

To summarise, all schools commented on how well children participated in the activities and that children noticed the difference (calmness, peaceful, 
less agitated) after engaging in mindfulness in their day-to-day experiences not just during the mindfulness exercise. There was only one school (School \#2) that reported a few children were easily distracted in the first few sessions, and did not engage immediately with the practices, but that from the third session, all students participated actively in the mindfulness exercises. In the follow-up questionnaire, it was evident that all schools were still engaging in some form of the mindfulness activities. The CDs provided by the mindfulness facilitator were seen as very helpful.

\section{Key finding 2: Students' ability to focus and pay attention}

After week 6, the teacher in School 1 noted improved focus from even those students who had previously been having difficulty focusing. Students were more attentive and friendlier in school 2 but the teacher was unsure whether it was a result of mindfulness or Positive Behaviour 4 Learning (PB4L, a school-wide behaviour programme). Slowing down was a theme in school 3 which allowed for greater focus, and the teacher noted "profound effects on a couple of children" who had previously been unable to sit still and were easily distracted, were now able to focus and pay attention. School 4 did not notice any substantial changes in this area during the programme. As noted by the teacher in school 5, "increased focus has become a spinoff from mindfulness".

Many schools identified that there were other disruptions going on in the school at the time but still an improved focus was noted over time. It is possible the sense of calm noted above, also has had an impact on the children's ability to focus and pay attention as well.

\section{Key finding 3: Improved relational skills}

Key findings from the journals and follow-up survey indicated improvements in conflict resolution, evidence of developing positive relationships, and an ability to see others' points of view. In school 1, following the session on compassion, the children engaged in a number of activities to turn their kind thoughts into actions including a series of lunchtime activities for children who did not want to participate in sports. Children in this school were more respectful, and were also solving problems with peers more quickly. For example, when there was a fight, the two children would calm down more quickly. The teacher commented, "I would suggest that most of the credit for this can go to mindfulness as the class are thinking about their actions instead of reacting". All of the schools noted positive development in student interactions with each other except for school 4. Students in school 2 were observed particularly engaging with and enjoying the practices for fostering kindness toward self and others. In school 3, this change in behaviour was not evidenced until after week 4. Prior to that, students had to be reminded to be mindful, but after week 4, teachers noticed that children were listening to others' points of view.

\section{Key finding 4: Increased calm and stress reduction for teachers}

The teacher in school 1 actively engaged in the activities and noted the positive effects on interactions with family members at home. Engaging with the activities assisted the teacher in school 2 particularly when she was sick in the middle of report writing. 
A key comment on participation from teacher 3 was "in class the ten minutes we spend starting each day with mindfulness really seems to set me and the class up a bit calmer". The teacher in school 4 which reported the least benefit for students also engaged personally the least but did seem interested in the activities particularly for personal stress reduction. The teacher in school 5 was observed by other teachers as being more calm and then summed up the value of the activities for teachers: "it really made me dig deeper into myself and sort out priorities".

Overall the journals have indicated positive benefits for students and the teachers in all school including personal stress reduction for teachers, but one school (\#4) perceived less benefit than the others. It is important to note that this teacher was the least engaged in the activities of all the teachers which highlights the importance of teachers engaging in the material provided as well as the necessity of providing professional development for teachers to model mindfulness within the classroom. The journal entries show that children had made some progress towards improved well-being. Calmness, ability to focus and improved relational skills following the use of these practices were sustained over time as noted in the follow-up journals.

\section{FURTHER FINDINGS}

Three additional themes were revealed from the journal entries during a subsequent examination of the data: the sustainability of the practices, how children flourished, and the application of mindfulness. These themes provide some insights into the long-term applications of mindfulness in schools. Firstly, sustainability was evident in the commitment of the teachers to the programme during the intervention and after. Two teachers commented on the positive effect of engaging with the practice on their personal lives. Many teachers had integrated the activities into their class programmes and some of the children were asking the teachers to lead them through the exercises.

All schools reported after three months that mindfulness continued to be a part of the classroom activities. Commitment was evident in all schools noting a minimum of two practices per week. Students settled more readily into the practices and most teachers were asking for additional mindfulness practices to share with students.

A second theme focused on how children flourished over time using the mindfulness practices. Although home practice was not a requirement, many children did take the opportunity to use the practices at home or share them with their parents. Four of the five teachers noted that outside the classroom children were more often able to, and more quickly regulated their emotions. Positive relationships with others were identified, as was a general sense of calm. Attention and focus were improved in all five schools. In the three-month follow-up survey, teachers noted that children continued to be calm and more relaxed, and grew in their ability to express feelings. In addition, teachers noted that the classroom culture was generally more friendly and cooperative. Interestingly, school 4 noted how much more visibly calm and focused children are following on-going mindfulness practices in the three-month follow-up survey which was not always evident in the teacher's observations during the programme delivery. 
Finally, we have noted that both teachers and children found ways to apply mindfulness as a way of improving focus and reducing stress to feel calm throughout the day. One teacher noted how mindful breathing was more calming than other traditional noisier cues to remind children to focus. Children were more aware when they were full during lunch. Many children chose to do mindful breathing to calm down. Mindful breathing was the on-going key practice noted in the follow-up surveys.

In the three-month follow-up survey, teachers indicated the desire for ongoing professional development for themselves, new practices for the children, and education for parents. These three suggestions will be our focus for future research and implementation of mindfulness practices in schools across New Zealand.

\section{DISCUSSION}

In summary, this pilot study indicated a number of key findings for students and teachers practicing mindfulness in schools. First, the teacher observations suggested that mindfulness contributed to increased experiences of calmness for students. With more participation in mindfulness, perhaps, greater calmness would be observed. Calmness in the classroom would potentially reduce conflicts between students and provide an opportunity to tap into the sometimes hidden abilities of students who might engage more in all classroom activities.

With improved focus and attention which results from mindfulness (Jha, et al., 2007; Semple \& Lee, 2008; Tang, et al., 2007), students might engage in classroom activities and participate more which can only have positive benefits for their academic achievement. As students engage in lessons for longer periods of time without becoming distracted or distracting others, previously used teaching strategies such as group work and discussion arguably may produce more fruitful results. The development of positive relationships and reduced conflict resolution may also enhance outcomes for group work and discussion in the classroom, and academic achievement.

Although this study was focused on positive well-being for children, we contend that stress reduction for teachers was also noted and can only enhance outcomes for students and for the classroom environment (Bernay, 2012; Soloway, Poulin, \& Mackenzie, 2011). Benefits of mindfulness for teachers has been noted in previous research conducted by Bernay (2014); Gold, et al. (2009); and Soloway, et al. (2011); and could also be an important aspect of future research.

These findings indicate the relevance of mindfulness to the development of the key competencies of the New Zealand curriculum. Improved focus and attention are important for thinking; the ability to self-calm is important for managing self. Effective conflict resolution skills and the ability to relate to others in positive ways contribute to the competency of relating to others. Additionally, the observation of organising lunchtime activities for others following the lesson on compassion is perhaps direct evidence of how mindfulness can help cultivate the competency of participating and contributing.

This study had a number of limitations, suggesting the need for further study. In this study, no randomised controls were used for comparison. The study is limited to five schools and a larger number of participants would have enhanced the project. The use of quantitative instruments focusing on specific 
aspects of mindfulness rather than totally relying on teacher reports will be utilised in our next study. A specific limitation of this study in relation to teacher's reports is the potential bias of teachers toward positive reflections when completing observations of their students.

Further study is recommended to demonstrate the effectiveness indicated in this pilot project. This might include interventions across a series of schools in New Zealand; a longitudinal study over at least three years; the use of quantitative instruments such as the Stirling Scale of Well-being or the Mindfulness Awareness and Attentions Survey adapted for Children (MAAS-C) in a randomised controlled trial. These positive benefits noted in this New Zealand study complement those from the North American studies discussed in the literature review and provide evidence of efficacy and the need for further research and wider implementation across New Zealand. 


\section{REFERENCES}

Baer, R. A., Smith, G. T., Hopkins, J., Krietemeyer, J., \& Toney, L. (2006). Using self-report assessment methods to explore facets of mindfulness. Assessment 13, 27-45. doi: 10.1177 /1073191105283504

Bernay, R. (2012). Mindfulness and the beginning teacher. Unpublished doctoral thesis.

Bernay, R. (2014). Mindfulness and the beginning teacher. Australian Journal of Teacher Education 39, 58-69. doi: 10.14221/ajte.2014v39n7.6

Biegel, G.M., \& Brown, K.W. (n.d). Assessing the efficacy of an adapted in-class mindfulness-based training programfor school-age children: A pilot study.

A Research Brief for Mindful Schools. Retrieved from: http://www.mindfulschools.org/pdf/

Mindful\%20Schools\%20Pilot\%20Study\%20

Whitepaper.pdf

Bishop, S. R., Lau, M., Shapiro, S., Carlson, L., Anderson, N. D., Carmody, J., Segal, Z., ... \& Devins, G. (2004). Mindfulness: A Proposed Operational Definition. Clinical Psychology: Science and Practice, 11, 230-241. doi:10.1093/clipsy/bph077

Britton, W. B., Haynes, P.L., Fridel, K.W., \& Bootzin, R. R. (2010). Polysomnographic and subjective profiles of sleep continuity before and after mindfulness-based cognitive therapy in partially remitted depression. Psychosomatic Medicine 72, 539-548. doi: 00333174/10/7206-0539

Bodner, T.E. \& Langer, E.J. (2001, June). Individual differences in mindfulness: The mindfulness/mindlessness scale. Poster presented 15 June, 2001 at the $13^{\text {th }}$ Annual American Psychological Society Conference. Toronto, Canada.

Brady, R. (2004). Schooled in the moment. Independent School, 64(1), 82-87. Retrieved from http://www.nais.org/pubs/is.cfm doi: 01459635

Braun, V., \& Clarke, V. (2006). Using thematic analysis in psychology. Qualitative Research in Psychology, 3, 77-101. doi:10.1191/1478088706qp063oa

Brown, J. \& Langer, E. (1990). Mindfulness and intelligence: A comparison. Educational psychologist. 25, 305-335. Retrieved from http://www.erlbaum.com /Journals/journals/EP/ep.htm

Brown, K. W., \& Ryan, R.M. (2003). The benefits of being present: Mindfulness and its role in psychological well-being. Journal of Personality and Social Psychology, 84, 822-848. doi: 10.1037/0022-3514.84.4.822

Creswell, J. (1994). Research design. Qualitative and quantitative approaches. Thousand Oaks, CA: Sage Publications.

Crotty, M. (1998). The foundations of social research. St. Leonards, Australia: Allen \& Unwin. 
Dendato, K. M., \& Diener, D. (1986). Effectiveness of cognitive/relaxation therapy and

study-skills training in reducing self-reported anxiety and improving the academic performance

of test-anxious students. Journal of Counselling Psychology, 33, 131-135. http://ovidsp.tx.ovid.com.ezproxy.aut.ac.nz/sp-

3.15.1b/ovidweb.cgi?\&S=BGHCFPCKOFDDOLPPNCKKIBLBPFEKAA00 \&Link+Set=S.sh.42.43.47.53|4|s|_10

Denzin, N., K., \& Lincoln, Y. S. (1994). Handbook of qualitative research. Thousand Oaks, CA: Sage Publications.

Desmond, C., \& Hanich, L. (2010). The effects of mindful awareness on the executive functions of students in an urban, low income middle school. Retrieved

from http://www.wellnessworksinschools.com/WWResearchReport2010.pdf

Fan, J., McCandliss, B. D., Sommer, T., Raz, A., \& Posner, M. I. (2002). Testing the efficiency and independence of attentional networks. Journal of Cognitive Neuroscience, 14, 340-347. doi: 10.1162/089892902317361886

Flook, L., Smalley, S.L., Kitil, M.J., Cho, J., Kaiser-Greenland, S., Locke, J., \& Kasari, C. (2008, April). A mindful awareness practice improves executive function in preschool children. Poster presented at the Center for Mindfulness in Medicine, Health Care, and Society $6^{\text {th }}$ Annual Conference, Worcester, MA.

Flook, L., Smalley, S. L., Kitil, M.J., Galla, B.M., Kaiser-Greenland, S., Locke, J., ... \& Kasari, C. (2010). Effects of mindful awareness practices on executive functions in elementary school children. Journal of Applied School Psychology, 26, 70-95. doi: 10.1080/15377900903379125

Fogarty, F. (2009). A comparison of mindfulness meditators and non-meditators following writing about negative emotional memories: Are their psychological and physiological responses different? Unpublished Masters thesis. University of Auckland. Auckland, New Zealand.

Gall, J. P. , Gall, M. D., \& Borg, W. R. (2005). Applying educational research: A practical guide. Sydney, Australia: Pearson.

Gilbert, P. (2009). The compassionate mind: A new approach to life's challenges. London, England: Constable.

Gold, E., Smith, A., Hopper, I., Herne, D., Tansey, G., \& Holland, C. (2009). Mindfulness-based stress reduction (MBSR) for primary school teachers. Journal of child and family studies. http://www.springerlink.com/ content/ j3031222w0067611/fulltext.html

Hart, T. (2001a). From information to transformation: Education for the evolution for consciousness. New York, NY: Peter Lang Publishing.

Hart, T. (2001b). Teaching for wisdom. Encounter: Education for meaning and social justice, 14(2), 3-16. Retrieved from http://www.great-ideas.org 
Hawn Foundation (2011). The MindUp Curriculum: Brain-focused strategies for learning and living. New York, NY: Scholastic.

Hölzel, B. K., Carmody, J., Vangel, M., Congleton, C., Yerramsett, S. M., Gard, T. and Lazar, S. W. (2011). Mindfulness practice leads to increases in regional brain gray matter density. Psychiatry Research: Neuroimagining 191, 36-43. doi:10.1016/j.pscychresns.2010.08.006

Jha, A. P., Krompinger, J., \& Baime, M. J. (2007). Mindfulness training modifies subsystems of attention. Cognitive, Affective and Behavioral Neuroscience, 7, 109-119. doi:10.3758/cabn.7.2.109

Joyce, A., Etty-Leal, JH., Zazryn, T., Hamilton, A., \& Hassed, C. (2010). Exploring a mindfulness meditation program on the mental health of upper primary children: A pilot study. Advances in School Mental Health Promotion 3, 17-25. doi: 10.108011754730X.2010.9715677

Kabat-Zinn, J. (2005) Coming to our senses: Healing ourselves and the world through mindfulness. New York, NY: Hyperion Press.

Kaiser Greenland, S. (2010). The mindful child: How to help your kid manage stress, become happier, kinder and more compassionate. New York, NY: Free Press.

Kinder, R. (2008). Wellness works in schools. Lancaster, PA: Kinder Associates LLC.

Kiselica, M., Baker, S., Thomas, R., \& Reedy, S. (1994). Effects of stress inoculation training on anxiety, stress, and academic performance among adolescents. Journal of Counselling Psychology, 41, 335-342. http://ovidsp.tx.ovid.com.ezproxy.aut.ac.nz/sp-

3.15.1b/ovidweb.cgi?\&S=CNBAFPPJJBDDOLNONCKKEAIBIPEGAA00 \&Link+Set=S.sh.22.23.27.31|11|s|_10

Lantieri, L. (2008). Building emotional intelligence: Techniques to cultivate inner strength in children. Boulder, CO: Sounds True.

Ludwig, D. S., \& Kabat-Zinn, J. (2008). Mindfulness in medicine. Journal of the American Medical Association. 300, 1350-1352. doi:10.1001/ jama.300.11.1350.

Mental Health Foundation of New Zealand (2011). An Overview of MindfulnessBased Interventions and their Evidence Base. Mental Health Foundation. $\begin{array}{llll}\text { Retrieved } \quad 30 & \text { September } & 2013\end{array}$ http://www.mentalhealth.org.nz/home/sitesearch/?query=overview+of+mindfulness \& $=0$ \&y=0

Mindful Schools (2012a). What We Do. In Mindful Schools. Retrieved 29 September 2013 from: http://www.mindfulschools.org/.

Mindful Schools (2012b). Students, educators, teachers - everyone benefits from mindfulness. In Mindful Schools. Retrieved 29 September 2013 from: http://www.mindfulschools.org/about-mindfulness/research/

Ministry of Education. (2007). The New Zealand Curriculum. Wellington, New Zealand: Learning Media. Retrieved from: http://nzcurriculum.tki.org.nz/The-New-Zealand-Curriculum 
Napoli, M., Krech, P.R., \& Holley, L.C. (2005). Mindfulness training in school students: The attention academy. Journal of Applied School Psychology, 21, 99-125. doi: 10.1300/J370v21n01_05

Saltzman, A. \& Goldin, P. (2008). Mindfulness-based stress reduction for school-age children. Acceptance and mindfulness treatments for children \& adolescents: A practitioner's guide. (pp. 139-161). Oakland, CA: New Harbinger Publications.

Schonert-Reichl, K.A. \& Stewart Lawlor, M. (2007a). Evaluation of the ME Program: Promoting children's social-emotional competence in school: Initial findings for the "Mindfulness Education" program. Paper presented at the annual meeting of the American Educational Research Association (AERA) 9-13 April, Chicago, IL.

Schonert-Reichl, K.A., \& Stewart Lawlor, M. (2007b). The Goldie Hawn Institute Mindfulness Matters Program: An evaluation of implementation across four sites. Proposed Research Plan. Vancouver, Canada: Hawn Institute. Retrieved from: thehawnfoundation.org

Schonert-Reichl, K.A. \& Stewart Lawlor, M. (2010). The effects of a mindfulness-based education program on pre- and early adolescents' well-being and social and emotional competence. Springer Science+Business Media online. doi: 10.1007/s12671-010-0011-8

Schonert-Reichl, K. A., Oberle, E., Stewart Lawlor, M., Abbott, D., Thomson, K., Oberlander, T. F., \& Diamond, A. (2015). Enhancing cognitive and socialemotional development through a simple-to-administer mindfulnessbased school program for elementary school children: A randomized controlled trial. Developmental Psychology 51(1), 52-66. doi: http://dx.org/10.1037/a0038454

Semple, R.J. \& Lee, J. (2008). Treating anxiety with mindfulness: Mindfulnessbased cognitive therapy for children. Acceptance and mindfulness treatments for children \& adolescents: A practitioner's guide. (pp. 63- 87). Oakland, CA: New Harbinger Publications.

Shapiro, S. L., Carlson, L., Astin, J., \& Freedman, B. (2006). Mechanisms of mindfulness. Journal of clinical psychology, 62(3), 373-386. doi: 10.1002/jclp.20237

Siegel, D. J. (2007). The mindful brain. New York, NY: W.W. Norton and Co., Inc.

Siegel, D. J. (2010). Mindsight: The new science of personal transformation. New York, NY: Bantam Books.

Simpson, J., \& Mapel, T. (2011). An investigation into the health benefits of mindfulness-based stress reduction (MBSR) for people living with a range of chronic physical illnesses in New Zealand. Journal of the New Zealand Medical Association 124(1338), 1-5. http://journal.nzma.org.nz/ journal/124-1338/4765/

Soloway, G. B., Poulin, P. A., \& Mackenzie, C. S. (2011). Preparing new teachers for the full catastrophe of the twenty-first century classroom: Integrating mindfulness training into initial teacher education. In A. Cohan 
\& A. Honigsfeld (Eds.), Breaking the mold of pre-service and in-service teacher education (pp. 219-227). Lanham, MD: R \& L Education.

Stake, R. E. (1995). The art of case study research. Thousand Oaks, CA: Sage Publications.

Tang, Y., Ma, Y., Wang, J., Fan, Y., Feng, S., Lu, Q., .. \& Posner, M.I. (2007). Short-term meditation training improves attention and self-regulation. PNAS, 104, 17152-17156. doi:10.1073/ pnas.0707678104

van Manen, M. (1990). Researching lived experience: Human science for an action sensitive pedagogy. London, Canada: University of Western Ontario.

Wenk-Sormaz, H. (2005). Meditation and habitual responding. Alternative therapies in health and medicine 11, 42-58. Retrieved 30 September, 2013 from http:// www.alternative-therapies.com

Willis, J. (2007). Introduction to ME: Mindfulness Education program. Vancouver, Canada: Goldie Hawn Foundation.

Yook, K., Lee, S.-H., Ryi, M., Kim, K.-H, Bhoi, T. I., Suh, S. Y., ... Kim, M. J. (2008). Usefulness of mindfulness-based cognitive therapy for treating insomnia in patients with anxiety disorders. Journal of Nervous and Mental Disease 196, 501-503. doi: 10.1097/ NMD.0b013e31817762ac

Manuscript Submitted: October 9, 2014

Manuscript Resubmitted April 27, 2015

Manuscript Accepted: May 6, 2015 


\section{ABOUT THE AUTHOR(S)}

GRANT RIX

Mental Health Foundation

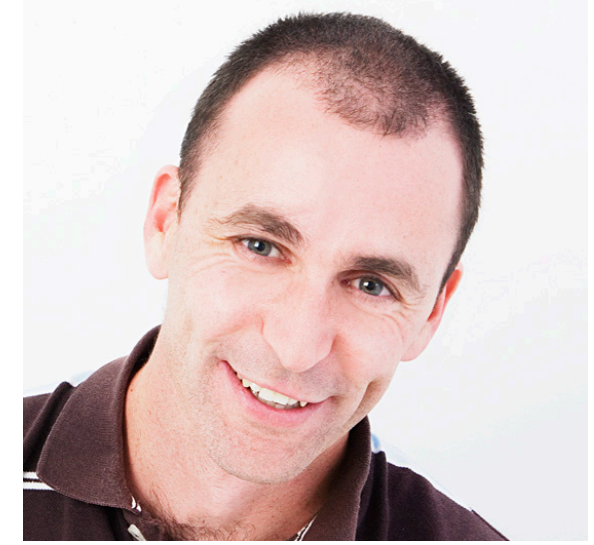

Grant Rix is the Project Manager of Mindfulness Promotion for the Mental Health Foundation of New Zealand. Grant is a mindfulness practitioner and teacher and has a background in public health promotion. He has a BA (Psych.) from Massey University, and is a graduate of a three year study and meditation academy that ran in the mid 2000s in the foothills of the Southern Alps.

Contact grant@mindfulaotearoa.nz

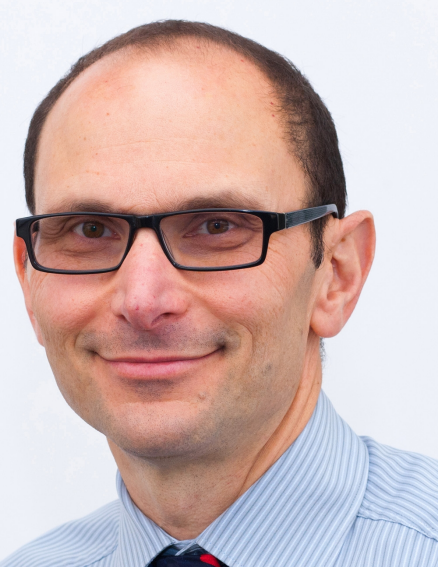

Ross Bernay is the Deputy Head of School in the School of Education at AUT University. Previously, he was a primary school teacher, deputy principal and principal in California and British Columbia. On arrival to New Zealand in 2003, Ross returned to teaching in the classroom before pursuing a career in initial teacher education. His doctorate traced the role of mindfulness in promoting well-being and reduced stress for a group of beginning primary school teachers. Ross incorporates mindfulness practices into his lectures at AUT University. Student feedback has highlighted the importance of including these practices for student teachers.

Contact rbernay@aut.ac.nz 